\title{
18. Exploring narrativity in data visualization in journalism
}

\author{
Wibke Weber
}

\begin{abstract}
Many news stories are based on data visualization, and storytelling with data has become a buzzword in journalism. But what exactly does storytelling with data mean? When does a data visualization tell a story? And what are narrative constituents in data visualization? This chapter first defines the key terms in this context: story, narrative, narrativity, showing and telling. Then, it sheds light on the various forms of narrativity in data visualization and, based on a corpus analysis of 73 data visualizations, describes the basic visual elements that constitute narrativity: the instance of a narrator, sequentiality, temporal dimension, and tellability. The paper concludes that understanding how data are transformed into visual stories is key to understanding how facts are shaped and communicated in society.
\end{abstract}

Keywords: Data visualization; Journalism; Narrativity; Storytelling; Telling; Showing

\section{Introduction}

Storytelling is deeply rooted in our society. From the very beginning of time people have told stories to convey ideas and thoughts, to share experience and knowledge, to express desires and feelings, or to remember the past. They have told stories with the purpose of informing and recording, explaining and persuading, understanding and entertaining. To this day, telling stories is a pivotal activity of our everyday lives. Stories help us to make sense of the world, to create individual and cultural identity, and to evoke emotions. Because of its emotional impact and cognitive effectiveness, storytelling has become an integral part of journalism.

Engebretsen, M. and H. Kennedy (eds.), Data Visualization in Society. Amsterdam: Amsterdam University Press, 2020 DOI 10.5117/9789463722902_CH18 
A lively discourse about storytelling in journalism has developed in recent years. Triggered by new technologies and increasing media convergence, new forms and hybrid genres have emerged (e.g. audio slideshows, gamified interactives, motion graphics, or VR pieces) — often subsumed by academics and practitioners under the vague term of multimedia storytelling, longform journalism, or online narrative journalism. These new products go far beyond the traditional text-based genres such as news, feature writing, or opinion. They cross the boundaries of images, texts and numbers, facts and fiction, distance and immersion; they conflate writing and drawing, telling and showing, narration and exploration; they combine objectivity with subjectivity, literacy with orality. Thus, they stand in the tradition of narrative journalism, also called literary journalism, which aims to find the private story behind the public story. One of these new forms that have gained tremendous momentum in the wake of data journalism is data visualization.

We are currently witnessing an increased use of data visualization in journalism, since data become only visible and publicly accessible through their visualization. Journalists and designers use not only standardized types of data visualizations like bar charts or maps, but also create new forms that are tailor-made in order to tell the story in the most understandable and engaging way. Here again, we come across the term storytelling: storytelling with data.

Storytelling is a buzzword in journalism, overused and with a fuzzy meaning. Studies in newsrooms have shown that when journalists use the term 'story' they often mean 'news', because both story and news refer to events (Merminod, 2016). When they talk about storytelling, they mean not only the text-linguistic practice of narrating but also describing, explaining, or arguing. The same applies to data visualization. "The phrase "data storytelling" has been associated with many things - data visualizations, infographics, dashboards, data presentations, and so on. [...] Data storytelling is a structured approach for communicating data insights, and it involves a combination of three key elements: data, visuals, and narrative' (Dykes, 2016). Here, another term comes into play: narrative. In text linguistics, the narrative mode is distinguished from the text modes of description, explanation, and argumentation (Brinker, 2010). In this chapter, I focus only on the narrative mode in data visualizations (for argumentation see Archer \& Noakes, this volume).

A term that often appears in the context of the narrative mode is showing. In journalism, trainers give the normative advice: 'Show, don't tell' (e.g. Mencher, 1997, p. 154). It means not describing a particular subject from the narrator's point of view (the narrator remains in the background), but allowing the reader to witness the events, to experience the emotions 
of the character, and to immerse him- or herself into the story through moment-by-moment actions and dialogues. 'Show, don't tell' is also the title of a workshop held at the Malofiej Summit-one of the most important events for information graphics and data visualization in journalism (see http://www.malofiejgraphics.com/). However, what does telling mean in data visualization, and what does showing mean? I will come back to this question later.

Against this backdrop, I want to explore the following terms throughout the chapter: story, narrative, narrativity, telling and showing, and what they mean in the context of data visualization. I focus primarily on journalistic pieces that are mainly based on data visualization or stand-alone graphics. The leading question is: what does narrativity mean in data visualization? Since more and more news stories are based on data, understanding the different forms of narrativity in data visualization in journalism is key to understanding and critiquing how meaning is made out of data, how this meaning is shaped by the process of visualization, and how knowledge is thus conveyed in society.

\section{Story, narrative, narrativity, telling and showing}

Story and narrativity are often used interchangeably. Both story and narrative have been defined in many ways depending on the discipline, scholarly approach, or professional field (Ryan, 2007; Bell, 1991; Genette, 1988, 1980; Lotman, 1977; Barthes \& Duisit, 1975, to mention but a few). For my purpose, I regard a narrative as a textual, visual, or multimodal representation that presents a story. As such, a narrative is the semiotic product of narrating (Genette, 1988, p. 14). Every narrative is based on a story and mediated by a narrator, the person or speech position from which the story originates, or 'the individual agent who serves as the answer to Genette's question qui parle?' (Margolin, 2014).

What defines story? On a very basic level, a story is a sequence of events or happenings that are temporally structured and coherently related to each other, involving one or more characters or anthropomorphic agents or objects. According to Genette, 'as soon as there is an action or an event, even a single one, there is a story because there is a transformation, a transition from an earlier state to a later and resultant state' (1988, p. 19). For him, the sentence 'I walk' is a minimal but whole story because it implies 'a state of departure and a state of arrival' (p. 19). A foundational definition of story is given by Forster (1927, p. 130): 'The king died, and then the queen died', whereas a plot adds causality to a story: 'The king died, and then the queen 
died of grief'. Story is not tied to a specific genre. It works as an underlying layer in a narrative as well as in other literary works such as dramas, poems, comics, movies, or data visualizations.

While story refers to what is being told, the distinction between telling and showing addresses how the story, that is, the events, are presented in a narrative. When Genette talks about telling vs. showing, he refers to the degree to which the narrating instance is present. "Showing" can be only a way of telling, and this way consists of both saying about it as much as one can, and saying this "much" as little as possible [...] —in other words, making one forget that it is the narrator telling' (Genette, 1980, p. 166). A 'pure narrative', the telling mode, is characterized as more distant, more mediated, and says less than the showing mode (p.163), whereas the showing mode gives the readers the illusion that they are shown the events of a story. Guided by the explanations of Klauk and Köppe (2014), Table 18.1 displays the main features of telling vs. showing.

Table 18.1 Telling vs. showing

\begin{tabular}{|c|c|c|}
\hline & Telling & Showing \\
\hline $\begin{array}{l}\text { Narrator and narrator's } \\
\text { spatial position towards } \\
\text { what is told }\end{array}$ & $\begin{array}{ll}\text { - } & \text { presence of a narrator } \\
\text { - } & \text { mediated presentation } \\
\text { - } & \text { remote distance } \\
\text { - } & \text { only what is worth } \\
& \text { telling is presented in } \\
& \text { the narrative }\end{array}$ & $\begin{array}{ll}\text { - } & \text { absence of a narrator } \\
\text { - } & \text { unmediated } \\
\text { presentation } \\
\text { - } \quad \text { close distance, as if the } \\
\text { events were revealed }\end{array}$ \\
\hline $\begin{array}{l}\text { Speed of unfolding the } \\
\text { narrative }\end{array}$ & $\begin{array}{l}\text { - fast speed, which means } \\
\text { less detailed information } \\
\text { - } \quad \text { focus on summary }\end{array}$ & $\begin{array}{l}\text { - } \quad \text { slow speed, which } \\
\text { means more detailed } \\
\text { information } \\
\text { - } \text { focus on scene }\end{array}$ \\
\hline Dialogue & $\begin{array}{l}\text { - } \quad \text { absence of dialogues } \\
\text { - } \quad \text { epic }\end{array}$ & $\begin{array}{l}\text { - } \quad \text { presence of dialogues } \\
\text { - } \quad \text { scenic }\end{array}$ \\
\hline Explicitness / implicitness & $\begin{array}{l}\text { - explicitness of } \\
\text { characters' traits, } \\
\text { themes, meanings, or } \\
\text { morals of the story }\end{array}$ & $\begin{array}{l}\text { - implicitness of } \\
\text { characters' traits, } \\
\text { themes, meanings, or } \\
\text { morals of the story }\end{array}$ \\
\hline Partiality / impartiality & $\begin{array}{l}\text { - partiality which includes } \\
\text { commentary and } \\
\text { subjective evaluation }\end{array}$ & $\begin{array}{l}\text { - impartiality and } \\
\text { objectivity }\end{array}$ \\
\hline Reader's perception & $\begin{array}{l}\text { - the reader gets the story } \\
\text { told }\end{array}$ & $\begin{array}{l}\text { - the reader witnesses the } \\
\text { events of the story }\end{array}$ \\
\hline
\end{tabular}

In the current discourse of narratology, there is a broad range of possible meanings of telling and showing and some of the features listed are 
contentious. Thus 'it remains and open question whether, or to what extent, these accounts allow for unification' (Klauk \& Köppe, 2014). In my context, Table 18.1 serves as a heuristic means for identifying narrative techniques in data visualization.

Narrativity is closely connected to story and narrative. Many concepts that define narrativity refer to fictional text (Abbott, 2011; Ryan, 2007). A definition of narrativity that is most suitable for the application to nonfictional genres such as data visualization is the set of conditions proposed by Ryan (2007). Ryan does not regard narrativity 'as a strictly binary feature, that is, as a property that a given text either has or doesn't have'. Instead she defines narrativity as 'a fuzzy set allowing variable degrees of membership, but centred on prototypical cases that everybody recognizes as stories' (2007, p. 28). Table 18.2 summarizes a few crucial constituents of narrativity along Ryan's set of conditions (pp. 28-31). With this sketchy framework in mind, I turn to a discussion of storytelling in data visualization.

\section{Table 18.2 Narrative constituents}

\begin{tabular}{|c|c|}
\hline $\begin{array}{l}\text { Spatial and temporal } \\
\text { dimension }\end{array}$ & $\begin{array}{l}\text { - The world is situated in time and undergoes a transformation } \\
\text { caused by non-habitual physical events. } \\
\text { - It is about individuated existents. } \\
\text { - Temporal transformation excludes pure explanation, descrip- } \\
\text { tion, or argumentation. }\end{array}$ \\
\hline Characters and events & $\begin{array}{l}\text { - It is about characters that react emotionally to the events, which } \\
\text { excludes weather reports and financial reports, for instance. } \\
\text { - Some actions by the characters must be purposeful, which } \\
\text { excludes mental events. }\end{array}$ \\
\hline Sequentiality & $\begin{array}{l}\text { - Sequence of events that are temporally structured and } \\
\text { coherently related to each other, which excludes lists or a } \\
\text { sequence of unconnected events. } \\
\text { - The occurrence of the events must be a fact for the story } \\
\text { world, which excludes hypotheses, instructions, or statements. } \\
\text { - Completeness (eventfulness): the whole story is presented, } \\
\text { which excludes fragmentary storytelling, e.g. breaking news } \\
\text { or news about ongoing events. }\end{array}$ \\
\hline Tellability & $\begin{array}{l}\text { - Giving an answer to: What's the point? } \\
\text { - Something meaningful that makes the story worth telling }\end{array}$ \\
\hline
\end{tabular}

\section{Storytelling and data visualization}

Several scholars have advanced the research on narrative techniques, rhetorical devices, and patterns in data visualization (e.g. Henry Riche, Hurter, Diakopoulos, \& Carpendale, 2018; Weber, Kennedy, \& Engebretsen, 2018; 


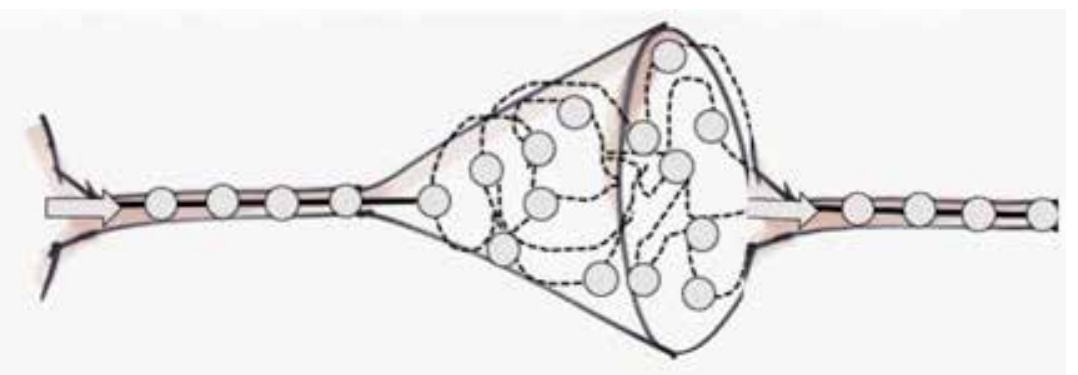

Figure 18.1. Telling, showing, telling. A modified version of the Martini-Glass structure. Illustration by W. Weber.

Brehmer, Lee, Bach, Henry Riche, \& Munzner, 2016; Hullman \& Diakopoulos, 2011; Segel \& Heer, 2010). One concept, which is often referred to, is the author-driven and reader-driven approach introduced by Segel and Heer (2010). By author-driven, they understand a strict linear path through the visualization, heavy messaging, and no interactivity, whereas reader-driven means 'no prescribed ordering of images, no messaging, and a high degree of interactivity' (p. 1146). In case of high interactivity, the user is given maximum information to explore the data visualization.

The so-called Martini-Glass structure (Figure 18.1), a term also coined by Segel and Heer (2010), is a combination of the author-driven and reader-driven approach and often employed by data visualization practitioners (Weber, Engebretsen, \& Kennedy, 2018). It comes close to what I have introduced earlier as telling vs. showing. At the beginning (the stem of the glass), the narrator, that is, the author or the production team, controls and handles the dataset from an authorial point of view (remote distance), telling the basic story found in the data in a linear way (sequentiality) by summarizing the main facts (fast speed) and emphasizing or annotating some points (partiality). Then, the data visualization opens up (at the mouth of the glass) and offers the user some room for exploration by showing the data (slow speed, close distance, impartiality), while the author steps back into the background. However, showing takes place in a limited frame predefined by the author who is in control again as soon as the user continues to click or scroll.

The author-driven/reader-driven approach, which addresses the production-reception level, can be compared to the distinction of 'explanatory' and 'exploratory', which is situated at the product level (Thudt et al., 2018, pp. 59-84; Young, Hermida, \& Fulda, 2017; Kirk, 2016, pp. 77-80; Barlow, 2014). The point here is whether the message found in the data visualization is explained, or whether the visualization is presented as an analysis tool so 
that users can explore the datasets themselves. Strictly speaking, exploratory and explanatory are separate modes for themselves and, therefore, cannot represent the narrative mode as defined above. However, these types are often subsumed by scholars under the broad term data-driven storytelling (e.g. Thudt et al., 2018). What can be stated, however, is that explanatory and exploratory elements can be part of an overarching narrative frame. The following section considers whether the various techniques that constitute narrativity can be found in journalistic data visualization.

\section{Constituents of narrativity in data visualization}

In order to tell a story in a data visualization, we need techniques and stylistic devices that constitute visual narrativity. I draw on (i) findings from related studies in the field of data visualization, and (ii) insights gained from my analysis of a corpus of 73 data visualizations. The corpus, which was built for the INDVIL research project, was compiled in a very pragmatic way by looking for the latest award-winning and shortlisted data visualizations in journalism that have been selected by a jury of experts because of their qualities and standards. ${ }^{1}$ These awards are the Malofiej Award 2018, the Data Journalism Awards 2018, and the Kantar Information is Beautiful Awards 2017. The majority of the data visualizations were produced by news organizations in Western Europe and the US. The analysis criterion relevant to my context was the mode in which the data visualization is predominantly presented: narrative (does it tell a story) vs. explanatory (does it explain something), argumentative (is it embedded in a text-based argumentation structure), or exploratory (free exploration of the data). In what follows, the techniques and stylistic devices that constitute the narrative mode as described in Table 18.1 and 18.2 are considered.

\section{Presence of a narrator}

While in fiction the story is presented by a narrator as a mediating instance, in journalism the story is presented by the real author or the production team, namely journalists, designers, and programmers. That means, the two different roles of narrator and real author that in narratology should be clearly

1 The research project INDVIL (Innovative Data Visualization and Visual-Numeric Literacy) is supported by the Research Council of Norway (NFR) and the Norwegian Media Authorities (RAM), www.indvil.org. 

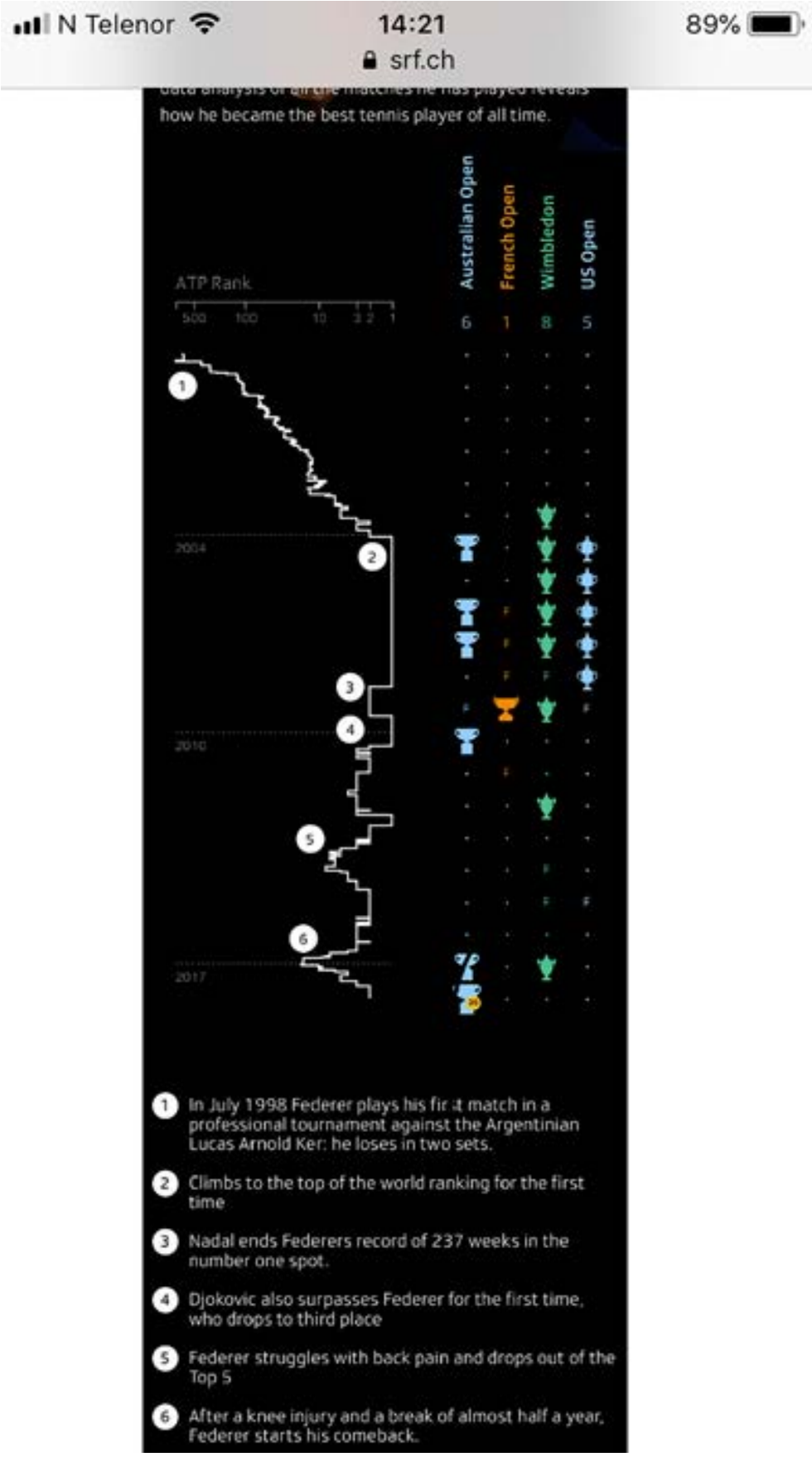

Figure 18.2. Screenshot of the intro of the data visualization '20 years, 20 titles', Mobile version. From '20 years, 20 titles', by A. Zehr et al., 2018. (https://www.srf.ch/static/srf-data/data/2018/ federer/en.html\#/en) Copyright SRF. Reprinted with permission. 
distinguished from each other, particularly in fiction, coincide. Looking at the text elements embedded in the visualization, titles, teasers, captions, or labels can give a hint to the author's presence and the narrative mode. The author can be present in the form of personal pronouns (we) or proper nouns as for example in 'An 18-month nationwide investigation by The Guardian reveals, for the first time, what really happens at journey's end' [8]. The temporal specification at the end of the sentence also points to the narrative mode. Verbs of movement or change do the same job as well as adverbs of time and place: 'After hurricane Maria, Puerto Rico was in the dark for 344 days, 6 hours and 43 minutes' [7], 'How California's Most Destructive Wildfire Spread, Hour by Hour' [11], 'How a Melting Arctic Changes Everything' [9]. In contrast, adverbs of manner are more likely to indicate the explanatory mode: 'Don't waste your time at Disneyland. Here's how to avoid the lines' [4], or 'We analyzed 100,000 drawings to show how culture shapes our instincts' [5].2

A narrator/author can also become visible in the form of tooltips [2], which are small text boxes that pop up when the user moves the mouse cursor over an item in the graphic. Narratorship too appears through highlighting, emphasizing, or annotating certain data, making elements salient, or pointing to statistical outliers. In the line graph of the data visualization '20 years, 20 titles' [12], important milestones of Roger Federer's career are numerically labelled and annotated in a legend (Figure 18.2).

Data visualizations that are organized like a slideshow (Figure 18.3) often show all features of a story: beginning, ending, and a change in between as well as causality. In the data visualization 'Mass exodus: the scale of the Rohingya crisis' [6], the narrator/author becomes visible by commenting that the numbers rose 'dramatically each day'. This data visualization, a stand-alone graphic, displays the increase of Rohingya refugees fleeing to Bangladesh. It is based on animation, another technique that supports narrativity. The animation works like a narrating instance which decides what is presented to the reader and worth telling, summarizes the events, and controls the speed in which the events unfold. The user is given no option to intervene or stop the animation, instead the user is told the events.

Another kind of audio narration, namely sonification, is used in the data visualization 'The sound of the substantial fall of the SPD' [10]. The line graph tells the story of the substantial fall of the Social Democratic Party of Germany (SPD), based on 3,838 poll ratings from January 1998 to the end of February 2018. The data team translated the ups and downs of the visible line into music. Thus, we cannot only see the data but also 

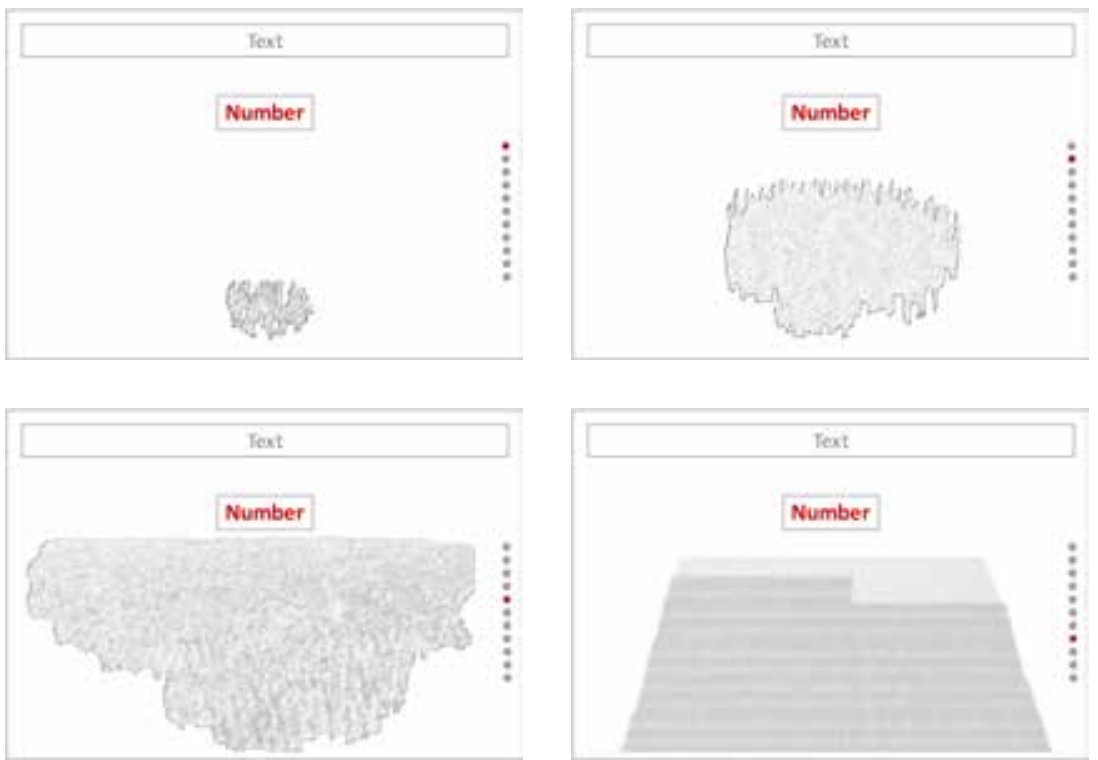

Figure 18.3. Sequential pattern with scrolling and zooming out. Drawn after the graphic 'Mass exodus: The scale of the Rohingya crisis' by C. Inton et al., 2017 (http://fingfx.thomsonreuters.com/ gfx/rngs/MYANMAR-ROHINGYA/010050XD232/index.html). Reuters Graphics.

hear it. The sonification, that is, transforming data into sound, works as a narrative comment using variables such as volume, pitch, duration, tempo, and rhythm. The deep final tone sounds dramatic and seems to be the end of the party. In data videos, the voice-over narrator can be a kind of omniscient narrator who comments on actions, events, or characters and ensures coherence between the sequences.

\section{Sequentiality}

Sequentiality can be realized in several ways. One option is to use the (parallax) scrolling technique. Here, the effect is twofold: stepping from one event to the next while scrolling down or pressing the arrow keys (Stolper, Lee, Henry Riche, \& Stasko, 2018, pp. 95-96), and thus, causing a transformation of the visualization. Telling stories by scrolling is called scrollytelling. The scrolling movement can be combined with zooming effects as the pattern in Figure 18.3 illustrates; it visualizes the dramatic increase of the Rohingya refugees [6]. First, the user has to scroll down, step-by-step, to see how fast the amount of refugees is growing; then, the story speeds up by replacing scrolling by animation. Each sequence is represented as a dot, which is lined up in a breadcrumb navigation placed on the right. While scrolling down is 
somewhat closer to the showing mode because the user is in control of the visualization and can decide whether to go forth or back, the animation represents the telling mode with fast speed and author's control.

In animation the transition from one narrative point to the next is performed smoothly and cohesively by the author; by contrast, in scrollytelling the sequences are linked through an interaction performed by the user. Next and previous buttons or the instruction 'click or press to continue', e.g., 'If you're black' [3], fulfil the same function as the horizontal or vertical scrolling. These data visualizations are called steppers because users have to click through the story step-by-step in a linear way to see how the story develops. The linking elements that combine the different sequences into a coherent whole can be for instance lines, arrows, or colour, e.g. using the same colour, while shape or size is changing. Another option for providing sequentiality is to show the different events as chapters in a navigation menu at the beginning of the story [2] or in a navigation bar [9].

\section{Visualization types for depicting change over time}

As mentioned above, the temporal dimension is crucial for storytelling. Therefore, timelines, time series graphs, flow maps (e.g. a Sankey diagram), slideshows, or data videos are well suited for storytelling. Maybe the most famous flow map is Charles Joseph Minard's map of the Russian campaign 1812-1813. 'By placing stroked lines on top of a geographic map, a flow map can depict the movement of a quantity in space and (implicitly) in time' (Heer, Bostock \& Ogievetsky, 2010, p. 63). A timeline consists of a sequence of events (happenings) in chronological order, whereas a time series graph shows how several variables have changed over a specific time period. It combines temporal data (when) with numerical data (how many).

To turn other charts into narratives, we must add a temporal dimension. A pie chart, a network diagram, or a treemap alone does not represent a story, they just present facts. However, a line graph that depicts how values have changed over a time period, can tell a story. 'If you show a bar chart with a stack on top of it to indicate growth between two points in time, well, you have added a time dimension' (Kirk, 2016, p. 160). Dynamic elements such as animated points, lines, or areas often show a movement from one point to another and thus a temporal change. Examples that show a change over time are again the 'Mass exodus' graphic [6] with its animated chart of the increase of refugees and the animated map 'Thousands Cried for Help as Houston 
Flooded' [1] that depicts the requests made by people who sought help during the Houston flooding.

Real-time data visualizations can be regarded as simultaneous narration. These are types of visualizations, e.g. maps, in which the data are immediately visualized after collecting them, so that the story develops simultaneously while looking at it. However, these are fragmentary stories with an open end, since neither the author nor the audience know how the story will end, and thus, do not fulfil the criterion of completeness. When Bounegru, Venturini, Gray, \& Jacomy (2017) ascribe narrative potential to non-sequential exploratory data visualizations such as interactive network diagrams, they mean that network visualizations can evoke a narrative script in the mind of the recipient. The question is, however, whether the reader is able to recognize and construe these network stories in the network diagram provided by the author.

\section{Tellability}

Tellability raises the questions of what makes a story interesting and appealing to the audience, what is the point of the story. Journalists are influenced by news values when they decide which story counts as news and which does not. News values are, for instance, relevance and impact of an event, negativity, proximity (geographical and cultural nearness), superlativeness, novelty (new and unexpected aspects), eliteness of individuals, and personalization which is the human face of an event (Caple \& Bednarek, 2016, p. 439).

Most of the data stories I considered meet the criterion of tellability since they focus on something that is novel to the audience, unexpected, or surprising. The topics that are covered in the data visualizations analysed deal with relevance and impact (racial discrimination [3]), superlativeness (Rohingya refugee crisis [6]), personalization (people seeking help during the Houston flood [1]), eliteness (celebrities and their life [12]), negativity (story of the melting Arctic [9]), novelty and personalization (what really happens to homeless people [8]).

\section{Conclusion}

The overarching question of this chapter was: What does narrativity mean in data visualization? Through my analysis of data visualizations in journalism and drawing on related studies on data-driven storytelling, I identified various techniques that constitute narrativity in data visualization. These are: 
- The instance of a narrator that becomes present in the form of micro text elements (e.g. title, teaser, captions, and tooltips), through design elements and stylistic devices (e.g. making some data more salient through colour or size), or through aural interpretation.

- Sequentiality, which can be expressed through scrolling, animation, and dynamic transition effects (e.g. zoom, dissolve, wipe, fade).

- The temporal dimension, which can be displayed best through data visualization types such as timelines, time series graphs, flow maps, slideshows, data videos, and other charts that show a change over time.

- Tellability, which addresses the journalistic question of what makes a story worth telling.

When it comes to the distinction between telling and showing, both can be found in narrative data visualizations. In the telling mode the message that is found in the data is communicated through a mediated instance, that is, the reader gets the message told. The showing mode comes into play as soon as the visualization prompts the reader to interact within a given set of options such as zooming, filtering, or selecting objects, but without leaving the narrative frame. This limited frame of interaction where the reader is given more control and the narrator remains in the background can be seen as a dialogue-like communication process. The extent to which this showing mode can be characterized as impartial and objective remains to be discussed since data visualizations are always subject to a design process and thus have subjective traits, even though they may appear objective and impersonal (Kennedy, Hill, Aiello, \& Allen, 2016).

Throughout this chapter, it has become clear that the journalistic advice 'Show, don't tell' does not fit well in the context of data visualization. Instead, 'Show and tell' would be more appropriate. The analysis of the corpus has also shown that it is a common practice to employ both modes in one single data story to attract and keep the reader's attention. At the same time, it has become obvious that the nature of journalistic storytelling is changing enormously, and data visualization is shaping this change. This change will affect how we shape facts, communicate news, and share knowledge in society in future.

\section{References}

Abbott, H. P. (2014). Narrativity. In: P. Hühn, J. C. Meister, J. Pier, W. Schmid (Eds.), The living handbook of narratology. Hamburg: Hamburg University. Retrieved August 24, 2018 from http://www.lhn.uni-hamburg.de/article/narrativity

Barlow, M. (2014). Data visualization: A new language for storytelling. Sebastopol, CA: O'Reilly Media. 
Barthes, R., \& Duisit, L. (1975). An introduction to the structural analysis of narrative. New Literary History, 6(2), 237-272. http://doi.org/10.2307/468419

Bell, A. (1991). The language of news media. Oxford: Blackwell.

Brehmer, M., Lee, B., Bach, B., Henry Riche, N., \& Munzner, T. (2016). Timelines revisited: A design space and considerations for expressive storytelling. IEEE Transactions on Visualization and Computer Graphics, 23(9), 2151-2164. http:// doi.org/10.1109/TVCG.2016.2614803

Brinker, K. (2010). Linguistische Textanalyse. Eine Einführung in Grundbegriffe und Methoden. Berlin: Erich Schmid.

Bounegru, L., Venturini, T., Gray, J., \& Jacomy, M. (2017). Narrating networks: Exploring the affordances of networks as storytelling devices in journalism. Digital Journalism, 5(6), 699-730. https://doi.org/10.1080/21670811.2016.1186497

Caple, H., \& Bednarek, M. (2016). Rethinking news values: What a discursive approach can tell us about the construction of news discourse and news photography.Journalism: Theory, Practice and Criticism, 17(4), 435-455. https://doi. org/10.1177/1464884914568078

Dykes, B. (2016, March 31). Data storytelling: The essential data science skill everyone needs. Forbes. Retrieved August 26, 2018 from https://www.forbes. $\mathrm{com} /$ sites/brentdykes/2016/03/31/data-storytelling-the-essential-data-scienceskill-everyone-needs/\#6126f53e52ad

Forster, E. M. (1927). Aspects of the novel. New York: Harcourt, Brace and Company. Genette, G. (1980). Narrative discourse: An essay in method (J. E. Lewin, Trans.). Ithaca, NY: Cornell University Press.

Genette, G. (1988). Narrative discourse revisited (J. E. Lewin, Trans.). Ithaca, NY: Cornell University Press.

Heer, J., Bostock, M., \& Ogievetsky, V. (2010). A tour through the visualization zoo. Communications of the ACM, 53(6), 59-67.

Henry Riche, N., Hurter, C., Diakopoulos, N., \& Carpendale, S. (Eds.). (2018). Datadriven storytellling. Boca Raton, FL: A K Peters/CRC Press.

Hullman, J., \& Diakopoulos, N. (2011). Visualization rhetoric: Framing effects in narrative visualization. IEEE Transactions on Visualization and Computer Graphics, $17(12)$, 2231-2240.

Kennedy, H., Hill, R. L., Aiello, G., \& Allen, W. (2016). The work that visualisation conventions do. Information, Communication and Society, 19(6), 715-735. https:// doi.org/10.108o/1369118X.2016.1153126

Kirk, A. (2016). Data visualisation: A handbookfor data driven design. London: Sage. Klauk, T., \& Köppe, T. (2014). Telling vs. Showing. In: P. Hühn, J. C. Meister, J. Pier, W. Schmid (Eds.), The living handbook of narratology. Hamburg: Hamburg University. Retrieved August 24, 2018 from http://www.lhn.uni-hamburg.de/ article/telling-vs-showing 
Lotman, J. (1977). The structure of the artistic text. Ann Arbor, MI: University of Michigan Press.

Margolin, U. (2014). Narrator. In: P. Hühn, J. C. Meister, J. Pier, W. Schmid (Eds.), The living handbook of narratology. Hamburg: Hamburg University. Retrieved August 24, 2018 from http://www.lhn.uni-hamburg.de/article/narrator

Mencher, M. (1997). News reporting and writing (7th ed.). London and Chicago: Brown \& Benchmark.

Merminod, G. (2016). Telling stories from the newsroom: A linguistic ethnographic account of dramatization in the broadcast news. Working Papers in Urban Language \& Literacies. Paper 197. Retrieved August 26, 2018 from http://www.academia. edu/28219120/WP197_Merminod_2016._Telling_stories_from_the_newsroom_A_ linguistic_ethnographic_account_of_dramatisation_in_the_broadcast_news

Ryan, M.-L. (2007). Toward a Definition of Narrative. In: D. Herman (Ed.), The Cambridge companion to narrative. (pp. 36-62). Cambridge: Cambridge University Press.

Segel, E., \& Heer, J. (2010). Narrative visualization: Telling stories with data. IEEE Transactions on Visualization and Computer Graphics, 16(6), 1139-1148. http:// doi.org/10.1109/TVCG.2010.179.

Stolper, C. D., Lee, B., Henry Riche, N., \& Stasko, J. (2018). Data-driven storytelling techniques: Analysis of a curated collection of visual stories. In: N. Henry Riche, C. Hurter, N. Diakopoulos, \& S. Carpendale (Eds.), Data-driven storytellling. (pp. 85-105). Boca Raton, FL: A K Peters/CRC Press.

Thudt, A., Walny, J., Gschwandtner, T., Dykes, J., \& Stasko, J. (2018). Exploration and explanation in data-driven storytelling. In: N. Henry Riche, C. Hurter, N. Diakopoulos, \& S. Carpendale (Eds.), Data-driven storytellling. (pp. 59-84). Boca Raton, FL: A K Peters/CRC Press.

Young, M. L., Hermida, A., \& Fulda, J. (2018). What makes for great data journalism? A content analysis of data journalism awards finalists 2012-2015. Journalism Practice, 12(1), 115-135. https://doi.org/10.1080/17512786.2016.1270171

Weber, W., Engebretsen, M., \& Kennedy, H. (2018). Data stories: Rethinking journalistic storytelling in the context of data journalism. Studies in Communication Sciences, 18(1), 191-206. https://doi.org/10.24434/j.scoms.2018.01.013

\section{Data visualizations: Examples taken from the corpus analysed}

[1] Aisch, G., Almukhtar, S., Ashkenas, J., Bloch, M., Carlsen, A., Delreal, J. A., Fessenden, F., ... Yourish, K. (2017, August 30). Thousands Cried for Help as Houston Flooded. The New York Times. Retrieved from https://www.nytimes. com/interactive/2017/08/3o/us/houston-flood-rescue-cries-for-help.html 
[2] Aisch, G., Almukhtar, S., Ashkenas, J., Bloch, M., Burgess, J., Carlsen, A., Fessenden, F., ... Williams, J. (2017, August 31). Maps: Tracking Harvey's Destructive Path Through Texas and Louisiana. The New York Times. Retrieved from https://www.nytimes.com/interactive/2017/08/24/us/hurricane-harvey-texas. html\#rainfall

[3] Bedi, N., \& Humburg, C. (2017, April 4). If you're black. Tampa Bay Times. Retrieved from http://www.tampabay.com/projects/2017/investigations/ florida-police-shootings/if-youre-black/

[4] Fox, J. Krishnakumar, P., \& Schleuss, J. (2017, July 12). Don't waste your time at Disneyland. Here's how to avoid the lines. Los Angeles Times. Retrieved from http://www.latimes.com/projects/la-fi-disneyland-ride-wait-time/\#ride-times

[5] Ha, T.-H., \& Sonnad, N. (2017, June 15). How do you draw a circle? Quartz. Retrieved from https://qz.com/994486/the-way-you-draw-circles-says-a-lot-about-you/

[6] Inton, C., Wu, J., Scarr, S., Cai, W., \& Singh, K. (2017, September 21). Mass exodus: the scale of the Rohingya crisis Mass exodus. Reuters Graphics. Retrieved from http://fingfx.thomsonreuters.com/gfx/rngs/MYANMARROHINGYA/010050XD232/index.html

[7] Lu, D., \& Alcantara, C. (2018, April 4 updated). After Hurricane Maria, Puerto Rico was in the dark for 344 days, 6 hours and 43 minutes. The Washington Post. Retrieved from https://www.washingtonpost.com/graphics/2017/national/ puerto-rico-hurricane-recovery/?utm_term=.5d71b968dbia

[8] Outside in America team (2017, December 20). Bussed out: How America moves its homeless. The Guardian. Retrieved from https://www.theguardian.com/ us-news/ng-interactive/2017/dec/2o/bussed-out-america-moves-homelesspeople-country-study

[9] Roston, E., \& Migliozzi, B. (2017, April 19). How a Melting Arctic Changes Everything. Bloomberg. Retrieved from https://www.bloomberg.com/ graphics/2017-arctic/

[10] Tröger, J., Pätzold, A., Timcke, M.-L., Klack, M., \& Wendler, D. (2018, March 1). Der Sound zum tiefen Fall der SPD (The substantial fall of the SPD). Berliner Morgenpost. Retrieved from https://interaktiv.morgenpost.de/spd-absturz-sound/

[11] Watkins, D., Griggs, T., Lee, C., Park, H. Singhvi, A. Wallace, T. Ward, J. (2017, October 21). How California's Most Destructive Wildfire Spread, Hour by Hour. The New York Times. Retrieved from https://www.nytimes.com/interactive/2017/10/21/ us/california-fire-damage-map.html

[12] Zehr, A., Schmidli, J. Nguyen, D.-Q., Boa, T., \& Guillemot, L. (2018, January 28). 20 years, 20 titles. SRF. Retrieved from https://www.srf.ch/static/srf-data/data/2018/ federer/en.html\#/en 


\section{About the author}

Wibke Weber is Professor of Media Linguistics at ZHAW Zurich University of Applied Sciences. Her areas of research are data visualization, information graphics, visual storytelling, visual semiotics, multimodality, and augmented and virtual reality. From 2001 to 2013 she worked as Professor of Information Design at Stuttgart Media University (HdM, Germany). 